\title{
An Optimization Algorithm to Determine Apparent Power of Active Filter
}

\author{
L.I. Kovernikova ${ }^{1}{ }^{2 *}$, Bui Ngoc Hung ${ }^{2,3}$, O.N. Vojtov ${ }^{1}$, L.V. Semenova ${ }^{1}$, Ha Thi Chuc ${ }^{3}$, Pham Duc Tien ${ }^{4}$
}

\author{
${ }^{1}$ Melentiev Energy Systems Institute of Siberian Branch of Russian Academy of Sciences, Irkutsk, Russia \\ ${ }^{2}$ Irkutsk National Research Technical University, Irkutsk, Russia \\ ${ }^{3}$ Ha Noi University of Mining and Geology, Ha Noi, Viet Nam \\ ${ }^{4}$ Wong Bi - TKV - Vinasovin Coal Company, Ha Noi, Viet Nam
}

\begin{abstract}
The coal grading plants in Viet Nam extensively apply induction motors. Induction motors consume active and reactive power from the power supply systems. The reactive power flowing through the electrical network creates active power losses. The reactive power received from power utilities reduces the load power factor at the node where coal sorting plants are connected to the supply network. Frequency-controlled induction motors introduce distortions into the electrical network because they are electrical equipment with a nonlinear current-voltage characteristic. Non-sinusoidal current and voltage cause additional losses of active power in the electrical network and electrical equipment, thereby shortening its service life, reducing the reliability of operation, and causing economic damage. Active filters can solve these problems. The paper proposes an optimization algorithm for determining the apparent power of the active filter, which provides the load power factor and power quality indices corresponding to the regulatory documents. The algorithm is used to calculate the apparent power of the active filter for the coal grading plant owned by the Vietnamese company "Cua OngVinacomin."
\end{abstract}

Index Terms-Active filter, algorithm, harmonic, load power factor, power quality index.

\footnotetext{
* Corresponding author.

E-mail: kovernikova@isem.irk.ru
}

http://dx.doi.org/10.38028/esr.2021.01.0003

Received March 05, 2021. Revised March 07, 2021.

Accepted March 13, 2021. Available online May 26, 2021.

This is an open access article under a Creative Commons Attribution-NonCommercial 4.0 International License.

(C) 2021 ESI SB RAS and authors. All rights reserved.

\section{INTRODUCTION}

Coal mining is one of the most important economic industries of Viet Nam. Mines and quarries have coal grading plants. Induction motors, primarily with frequency control, drive the manufacturing equipment of the plants. They are nonlinear loads for the power supply

system and distort power quality. The harmonic factors of voltage exceed the established standards [1]. Voltages and currents contain both harmonics and interharmonics [2]. The load power factors are lower than the value established by the normative documents [3].

In [4-7], the authors determine the active filter power to reduce the voltage and current harmonics in the electrical network. The power of the active filter is not only determined by the power of the harmonics. The use of the active filter is not confined only by the need to reduce harmonic values. Many consumers have additional economic losses because their electrical equipment receives reactive power from the supply network. In this context, the load power factor at the node connecting the power supply system of consumers to the supply network is lower than the standard value established for consumers. In [8-11], the authors use the active filter to compensate for reactive power and reduce harmonics. The authors of these papers do not consider active power losses due to reactive power transmission through the electrical network. Consumers have to pay for these losses and thus face additional economic damage. In [12-15], the authors determine the power of active filter to compensate for reactive power and reduce the values of harmonics, thereby providing the minimum losses of active power during the transmission of reactive power and the flow of harmonic currents in the electrical network of the power supply system.

The paper is concerned with an analysis of the power supply system of the coal grading plant, and results of the power quality tests. It formulates an optimization 


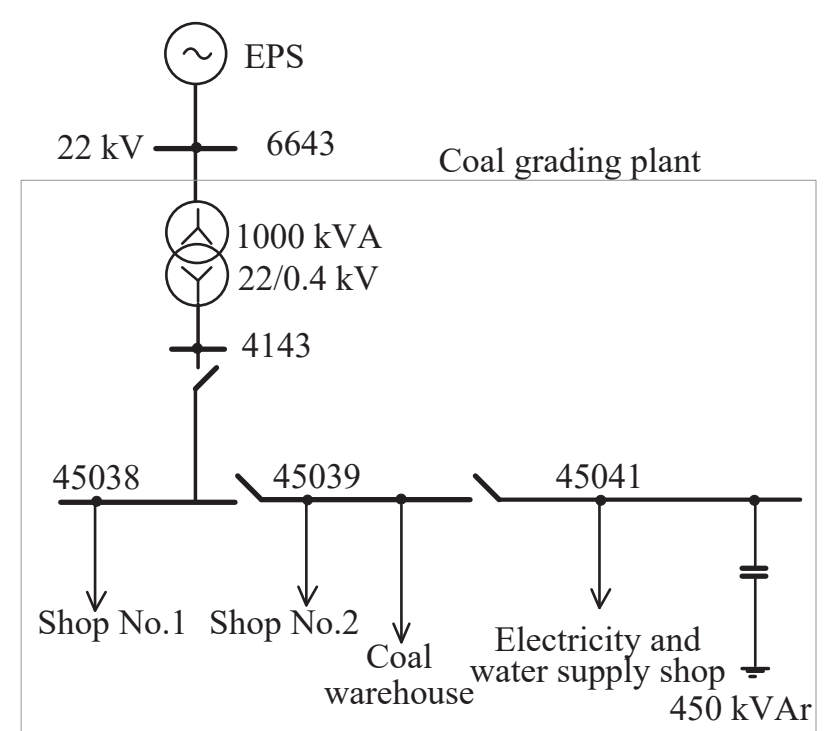

Fig. 1. Power supply system of the coal grading plant.

problem, describes an algorithm to determine the apparent power of the active filter, and presents specially designed software and results of the active filter apparent power calculation for the coal grading plant of the company "Cua Ong-Vinacomin."

\section{CHARACTERISTIC OF THE POWER SUPPLY SYSTEM AND LOADS OF THE COAL GRADING PLANT}

Fig. 1 presents a scheme of the power supply system of the coal grading plant.

Electrical power from the $22 \mathrm{kV}$ substation buses of the power supply utility (node 6643) is supplied to the $0.4 \mathrm{kV}$ network of the power supply system of the coal grading plant (node 4143 ) by the $1000 \mathrm{kVA}$ step-down transformer that belongs to the plant. The distance between nodes 4143 and 45038 is 60 meters. The total length of the $0.4 \mathrm{kV}$ electrical network exceeds $12 \mathrm{~km}$. The plant has two coal grading shops (shop No.1, shop No. 2), a shop of electricity and water supply, and a coal warehouse. Coal is mined in the quarry and transported to the warehouse of the coal grading plant. In the warehouse, the excavator unloads coal on the conveyor. The conveyor delivers coal to the shops for grading it by size. Fifty-eight induction motors with a capacity of 4 to $185 \mathrm{~kW}$ put the technological equipment of the shops into operation.

The following indices and norms for their values were established in [1] to assess voltage and current values in the $0.4 \mathrm{kV}$ network:

- the voltage deviation $|\delta U| \leq 5.0 \%$;

- the total harmonic distortion $K_{U} \leq 6.5 \%$;

- the $h$-th harmonic factor of voltage $K_{U(h)} \leq 3 \%$;

- the $h$-th harmonic factor of current $K_{I(h)} \leq 12 \%$.

In [2], the load power factor $(\cos \varphi)$ at the connection node of the plant to the supply network should meet the condition $\cos \varphi \geq 0.85$. If this condition is not fulfilled, the company, owner of the plant, pays penalties to the power
Table 1. Measured $\delta U, K_{U}, \%$.

\begin{tabular}{lccc}
\hline \hline Parameter & Phase A & Phase B & Phase C \\
\hline$\delta U_{\max }$ & 4.1 & 4.5 & 4.6 \\
\hline$\delta U_{\min }$ & -1.3 & -1.7 & -1.4 \\
\hline$\left|\delta U_{\text {norm }}\right|$ & & $\leq 5.0$ & \\
\hline$K_{U \max }$ & $\mathbf{1 6 . 8}$ & $\mathbf{1 5 . 3}$ & $\mathbf{1 7 . 1}$ \\
\hline$K_{\text {Unorm }}$ & & $\leq 6.5$ & \\
\hline \hline
\end{tabular}

Table 2. Measured $K_{U(h)}, K_{I(h)}, \%$.

\begin{tabular}{lccccccc}
\hline \hline \multirow{2}{*}{ Parameter } & \multicolumn{7}{c}{ Harmonic } \\
\cline { 2 - 8 } & 3 & 5 & 7 & 11 & 13 & 17 & 23 \\
\hline$K_{U(h) \max A}$ & 2.5 & $\mathbf{1 2 . 7}$ & $\mathbf{1 2 . 8}$ & $\mathbf{4 . 6}$ & 2.1 & $\mathbf{3 . 3}$ & $\mathbf{3 . 1}$ \\
\hline$K_{U(h) \max B}$ & $\mathbf{3 . 9}$ & $\mathbf{1 2 . 3}$ & $\mathbf{1 1 . 8}$ & $\mathbf{4 . 6}$ & $\mathbf{3 . 1}$ & 2.7 & 2.8 \\
\hline$K_{U(h) \max C}$ & 2.0 & $\mathbf{1 2 . 3}$ & $\mathbf{1 2 . 8}$ & $\mathbf{3 . 6}$ & 2.8 & $\mathbf{3 . 4}$ & $\mathbf{3 . 4}$ \\
\hline$K_{U(h) \operatorname{morm}}$ & & & & $\leq 3.0$ & & & \\
\hline$K_{I(h) \max A}$ & 7.1 & 6.8 & 6.7 & 3.9 & 1.9 & 2.3 & 2.7 \\
\hline$K_{I(n) \max B}$ & 3.9 & 4.2 & 1.7 & 0.8 & 1.1 & 0.5 & 0.4 \\
\hline$K_{I(h) \max C}$ & 3.6 & 4.9 & 3.3 & 1.2 & 1.7 & 1.5 & 1.2 \\
\hline$K_{I(h) \text { morm }}$ & & \multicolumn{7}{c}{$\leq 12.0$} & & & \\
\hline \hline
\end{tabular}

Table 3. Measured $K_{U(M)}, \%, I_{(M)}$, A.

\begin{tabular}{lccccccc}
\hline \hline \multirow{2}{*}{ Parameter } & \multicolumn{7}{c}{ Interharmonic } \\
\cline { 2 - 8 } & 1.5 & 3.5 & 5.5 & 7.5 & 17.5 & 19.5 & 21.5 \\
\hline$K_{U(m) \max A}$ & 3.9 & 1.0 & 1.7 & 1.8 & 1.2 & 1.5 & 2.3 \\
\hline$K_{U(m) \max B}$ & 3.3 & 0.8 & 1.9 & 1.9 & 1.0 & 1.3 & 2.3 \\
\hline$K_{U(m) \max C}$ & 3.8 & 0.9 & 0.9 & 1.2 & 1.7 & 1.7 & 1.7 \\
\hline$I_{(m) \max A}$ & 16.6 & 6.0 & 5.1 & 4.3 & 7.5 & 8.5 & 9.6 \\
\hline$I_{(m) \max B}$ & 17.2 & 4.8 & 5.0 & 2.7 & 1.9 & 2.7 & 3.2 \\
\hline$I_{(m) \max C}$ & 18.0 & 7.3 & 6.4 & 5.3 & 9.2 & 9.7 & 7.5 \\
\hline \hline
\end{tabular}

Table 4. Measured $\cos \varphi$, p.u.

\begin{tabular}{lccc}
\hline \hline \multicolumn{1}{c}{ Parameter } & Phase A & Phase B & Phase C \\
\hline $\cos \varphi_{\max }$ & 0.98 & 0.92 & 0.99 \\
\hline $\cos \varphi_{\min }$ & 0.89 & $\mathbf{0 . 7 2}$ & 0.89 \\
\hline $\cos \varphi_{\text {norm }}$ & $\geq 0.85$ \\
\hline \hline
\end{tabular}

supply utility. The value of $\cos \varphi$ can be low because of large reactive power consumption by the electrical motors of the plant, active power losses when transmitted over the electrical network, and losses caused by harmonics and interharmonics. Power quality indices and the value of $\cos \varphi$ at node 4143 were tested.

\section{RESULTS OF THE ELECTRICAL ENERGY TESTS}

The tests included 24-hour measurements of the voltage and current quality indices and $\cos \varphi$ by the device PQBox150 [16] with a time interval of measurements equal to 1 second.

Table 1 presents the measured values of $\delta U$, which meet the requirements [1]. The Table also shows the measured values of $K_{U}$ and their normative values from [1]. The measured values of $K_{U}$ exceed the norm more than twice. They are shown in bold type.

Table 2 presents the measured and normative values of $K_{U(h)}$ and $K_{I(h)}$ for the harmonics that exceed the norms 


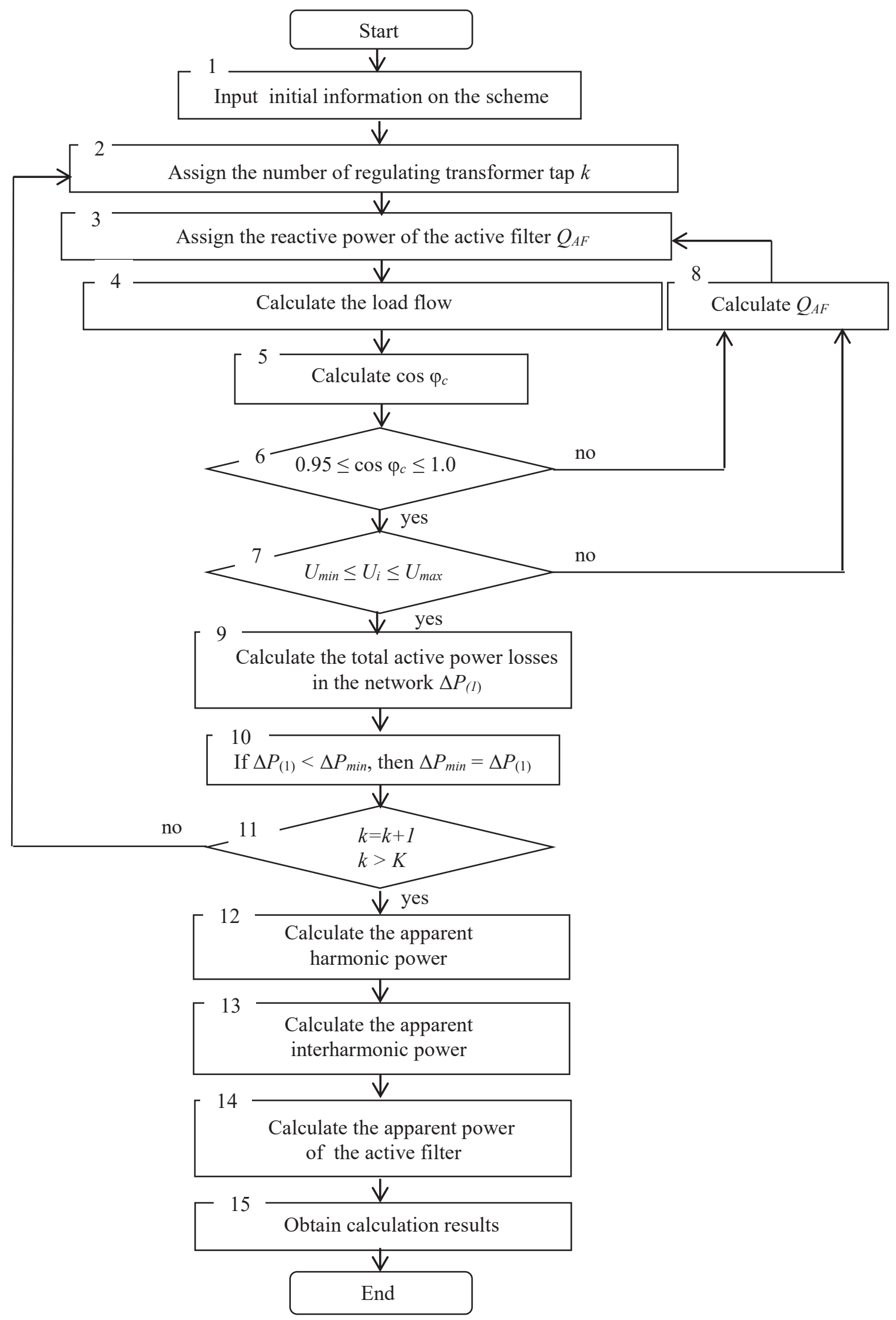

Fig. 2. Block-diagram of the algorithm to determine the power of the active filter. 

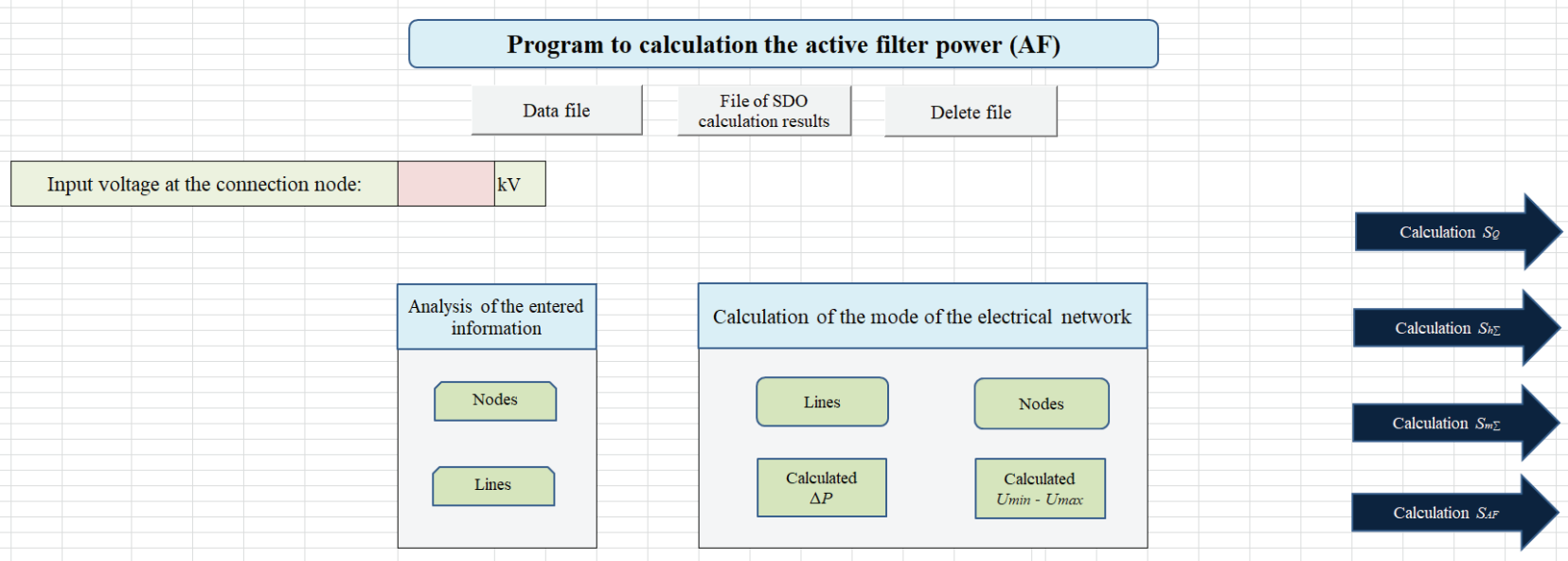

Fig. 3. Sheet 1 of the program.

most frequently [1]. The measured values of $K_{I(h)}$ are not higher than the normative value.

The measured values of $K_{U(m)}$ for some interharmonics and the values of currents $I_{(m) \max }$ of these interharmonics ( $m$ - the number of the interharmonic) are given in Table 3. The normative values for them are not determined.

The measured values of $\cos \varphi$ and its normative value determined in [3] are shown in Table 4. At phase B, the value of $\cos \varphi$ is lower than the norm.

The problems caused by harmonics, interharmonics, and $\cos \varphi$ can be resolved using a shunt active filter connected to the network in parallel to the nonlinear load [7-15, 17-20].

\section{OPTIMIZATION PROBLEM TO DETERMINE THE POWER OF THE ACTIVE FILTER}

The power of the active filter is determined by the reactive power to be generated to compensate for the reactive power of load and apparent power required to get rid of harmonics and interharmonics of the current at the point of the filter connection to the network. This can be achieved by solving an optimization problem with the objective function assumed to be the minimum active power losses in the power system network after installation of the active filter, i.e.,

$$
\sum_{h=1}^{H} \Delta P_{(h)}+\sum_{m=1}^{M} \Delta P_{\left(m+\frac{1}{2}\right)}=\min ,
$$

where $H$ is the highest number of the harmonic, $(M-1 / 2)$ is the highest number of interharmonic. In this case, the following constraints are to be met

$$
\begin{aligned}
& 0.95 \leq \cos \varphi \leq 1.0, \\
& U_{\text {min }} \leq U_{i} \leq U_{\max }, \\
& K_{U(h) \min } \leq K_{U(h) f} \leq K_{U(h) \max }, \\
& K_{U \min } \leq K_{U f} \leq K_{U \max }, \\
& K_{I(h) \min } \leq K_{I(h) f} \leq K_{I(h) \max },
\end{aligned}
$$

where $i$ is the network node number; $U_{i}$ is the voltage of the fundamental frequency; $U_{\min }, U_{\max }$ are the normative minimum and maximum voltages of the fundamental frequency; $\cos \varphi$ is the load power factor at the node connecting the plant to the supply network; $K_{U(h) f}$ is the $h$-th harmonic factor of voltage after installation of the active filter; $K_{U(h) \min }, K_{U(h) \max }$ are the normative maximum and minimum of the $h$-th harmonic factor of voltages; $K_{U f}$ is the total harmonic distortion after installation of the active filter; $K_{U \min }, K_{U \max }$ are the normative maximum and minimum of the total harmonic distortion; $K_{I(h) f}$ is the $h$-th harmonic factor of current after installation of the active filter; $K_{I(h) \text { min }}, K_{I(h) \text { max }}$ are the normative maximum and minimum of the $h$-th harmonic factor of current. Constraint (2) was established by the company "Cua OngVinacomin".

The optimization problem consists of three subproblems:

1. calculation of the apparent power of the active filter to provide the normative $\cos \varphi$;

2. calculation of the apparent power of the active filter to eliminate current harmonics;

Table 5. $Q_{A F}$ and $\Delta P_{(1) \Sigma}$ calculated by the algorithm.

\begin{tabular}{ccc}
\hline \hline$U_{4143}, \mathrm{kV}$ & $Q_{A F}, \mathrm{kVAr}$ & $\Delta P_{(1) \Sigma}, \mathrm{kW}$ \\
\hline 0.38 & 350 & 297 \\
\hline 0.39 & 480 & 290 \\
\hline 0.40 & 330 & 192 \\
\hline 0.41 & 450 & 134 \\
\hline 0.42 & 580 & 110 \\
\hline \hline
\end{tabular}

Table 6. $U_{\min }, U_{\max }$, and $\cos \varphi_{4143}$ calculated by the algorithm.

\begin{tabular}{cccc}
\hline \hline$U_{4143}, \mathrm{kV}$ & cos $\phi_{4143}$, p.u. & $U_{\min }, \mathrm{kV}$ & $U_{\max }, \mathrm{kV}$ \\
\hline 0.38 & 0.98 & 0.38 & 0.39 \\
\hline 0.39 & 0.97 & 0.38 & 0.39 \\
\hline 0.40 & 1.00 & 0.38 & 0.39 \\
\hline 0.41 & 0.99 & 0.38 & 0.41 \\
\hline 0.42 & 1.00 & 0.38 & 0.41 \\
\hline \hline
\end{tabular}

Table 7. Active, reactive, and apparent powers of harmonics.

\begin{tabular}{rccc}
\hline \hline \multicolumn{1}{c}{ Parameter } & Phase A & Phase B & Phase C \\
\hline$P_{h}, \mathrm{~kW}$ & 8.9 & 6.9 & 7.2 \\
\hline$Q_{h}, \mathrm{kVAr}$ & 11.0 & 7.3 & 14.4 \\
\hline$S_{h}, \mathrm{kVA}$ & 14.1 & 10.1 & 16.1 \\
\hline \hline
\end{tabular}




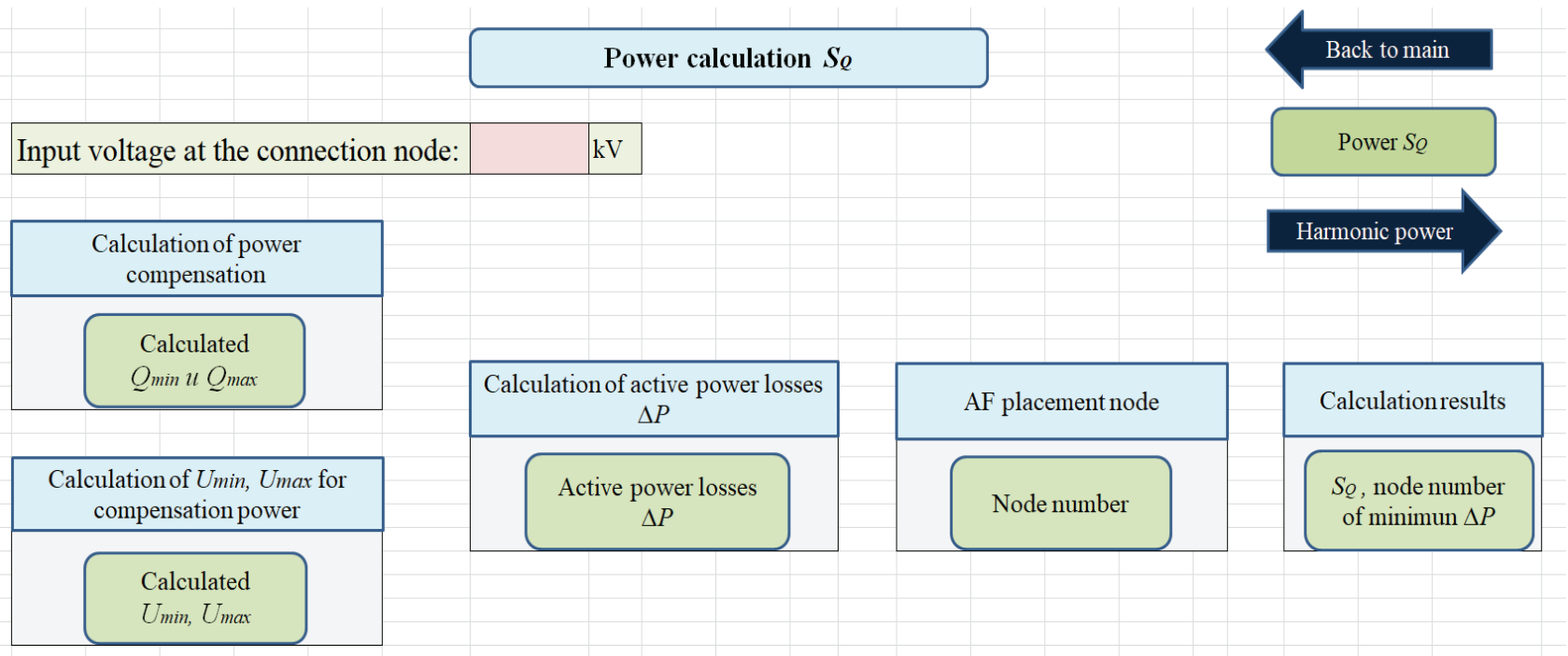

Fig. 4. Sheet 2 of the program.

3. calculation of the apparent power of the active harmonic filter to eliminate current interharmonics.

The first subproblem is formulated as follows: minimize the total active power losses in the network at the fundamental frequency, i.e.

$$
\Delta P_{(1)}=\min .
$$

In this case, constraints (2) and (3) should be fulfilled. If a node for active filter installation is not assigned, all nodes of the network must be considered as candidates for installation. The algorithm must consider transformer capabilities of voltage control on the lower side with the connected load. The suggested algorithm was developed based on the software "SDO" to calculate the fundamental frequency load flow [21-22]. The block diagram of the algorithm is presented in Fig. 2 .

Block 1. Input initial information on the electrical network scheme.

Block 2. Assign the number of transformer tap $k$, $k=\overline{1, K}, K$ is the quantity of taps.

Block 3. Assign the reactive power value of the active filter at the first step $Q_{A F}=0$.

Block 4. Calculate the load flow.

Block 5. Calculate $\cos \varphi$ at the connection node of the power supply system of the plant to the supply network based on the results of calculation using the expression $\cos \varphi_{c}=P_{i j} / \sqrt{P_{i j}^{2}+Q_{i j}^{2}}$, where "c" is an abbreviation of "calculated," $P_{i j}$ and $Q_{i j}$ are the active and reactive powers, $i, j$ are the network node numbers.

Block 6. Test fulfillment of constraint (2). If it is fulfilled, go to Block 7, otherwise, go to Block 8

Block 7. Test fulfillment of constraint (3) at all network nodes. If it is fulfilled, go to Block 9, otherwise, go to Block 8 .

Block 8. Calculate the reactive power of the active filter. The reactive power is calculated as

$$
Q_{A F}=P_{i j}\left(\operatorname{tg} \varphi_{c}-\operatorname{tg} \varphi_{d}\right) \text {, }
$$

where " $d$ " is an abbreviation of "desired." The value of $\operatorname{tg} \varphi_{c}$ is determined based on $\cos \varphi_{c}$. The value of $\operatorname{tg} \varphi_{d}$ is calculated using constraint (2). Since the feasible value of $\cos \varphi$ is within the interval

$$
\cos \varphi_{\min } \leq \cos \varphi \leq \cos \varphi_{\max },
$$

the value of the reactive power of the active filter is also within the interval

$$
Q_{\min } \leq Q_{A F} \leq Q_{\max }
$$

The required phase angle $\varphi_{d}$ should be calculated using $\cos \varphi_{\min }$ and $\cos \varphi_{\max }$. The highest and lowest values of $Q_{A F}$ are calculated by the expressions

$$
\begin{aligned}
& Q_{\text {min }}=P_{i j}\left(\operatorname{tg} \varphi_{c}-\operatorname{tg} \varphi_{\text {min }}\right), \\
& Q_{\text {max }}=P_{i j}\left(\operatorname{tg} \varphi_{c}-\operatorname{tg} \varphi_{\text {max }}\right) .
\end{aligned}
$$

Block 9. Calculate the total active power losses in the network based on the load flow calculation.

Block 10. Compare the active power losses of the preceding calculation step with the losses of the current step to determine minimum losses, namely, if

$$
\Delta P_{(1)}<\Delta P_{\text {min }} \text {, then } \Delta P_{\text {min }}=\Delta P_{(1)} \text {. }
$$

Block 11. Change the number of the transformer tap $k=k+1$. If $k>K$, then go to Block 12, if the condition is not fulfilled, go to Block 2 .

Block 12. Minimize the active power losses caused by harmonics in the network, i.e., $\sum_{h=2}^{H} \Delta P_{(h)}=\min$.

In this case, constraints (4)-(6) should be met by eliminating the harmonics of current with the help of the active filter at the node of filter connection. The apparent harmonic power is calculated as $S_{h \dot{C}}=\sqrt{P_{h}^{2}+Q_{h}^{2}} \quad$ [23], where

$$
\begin{gathered}
P_{h}=\sum_{h=2}^{H} U_{h} I_{h} \cos \varphi_{h}, \\
Q_{h}=\sum_{h=2}^{H} U_{h} I_{h} \sin \varphi_{h}
\end{gathered}
$$

were calculated by the measured voltages $U_{h}$, currents $I_{h}$ and phase angle $\varphi_{h}$. 


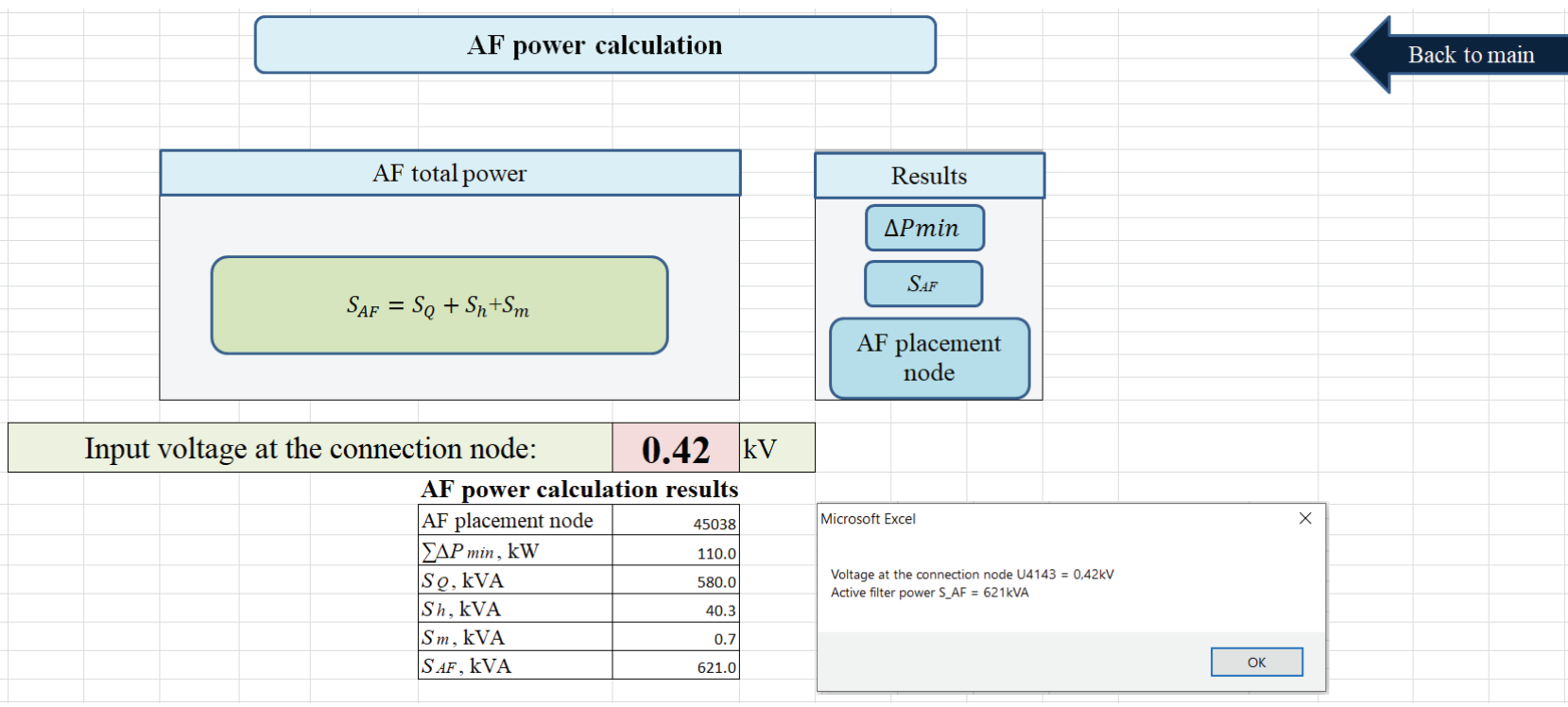

Fig. 5. Sheet 5 of the program.

Block 13. Minimize the active power losses caused by the interharmonics in the network, i.e.,

$$
\sum_{m=1}^{M} \Delta P_{\left(m+\frac{1}{2}\right)}=\min .
$$

For this purpose, the interharmonics of current should be eliminated by the active filter at the node of filter connection. The apparent power of interharmonics is calculated as $S_{m \Sigma}=\sum_{m=1}^{M} U_{m+1 / 2} I_{m+1 / 2}$ by the measured voltages $U_{m}$ and currents $I_{m}$.

Block 14. Calculate the apparent power of the active filter as a sum of three powers:

$$
S_{A F}=S_{Q A F}+S_{h \Sigma}+S_{m \Sigma} \text {. }
$$

Block 15. Obtain calculation results.

\section{THE COMPUTER PROGRAM TO CALCULATE THE ACTIVE FILTER POWER}

The computer program [24] was developed based on the algorithm built to determine the active filter power presented in Fig. 2. It is written in MS Excel and the programming environment Visual Basic for Windows applications. The program is designed to determine the apparent active filter power to compensate for the reactive load power for improving the power factor, and eliminating harmonics and interharmonics. The program makes it possible to determine a network node for placing an active filter.

The computer program component of the mentioned software "The stationary feasible optimal condition" (the software "SDO") is applied to calculate the value of power to be generated by the active filter for compensation for the reactive load power and to determine the network node for installation of the active filter [20-21]. This software is intended for the calculation of the steady-state conditions in electrical networks. It implements algorithms for calculation of feasible and optimal conditions in terms of the active and reactive power losses in the electrical networks with different voltage levels, including the steadystate unbalanced conditions of low-voltage distribution networks.

The program for calculation of active load power filter consists of five MS Excel sheets: sheet 1 is "Primary", sheet 2 is "Power $Q_{A F}$ ", sheet 3 is "Harmonics power $S_{h}$ ", sheet 4 is "Interharmonics power $S_{m}$ ", sheet 5 is "Power $S_{A F}$ ". Figure 3 presents the first sheet as an example. The fundamental frequency load flow and the comparative evaluation of $\cos \varphi$ and $U_{k}$ values, which were measured and calculated using the software "SDO" at the node connecting the power supply system of the plant to the supply network, were calculated using the commands of the first sheet. Comparison of the calculated parameters with the results of measurements and their close values confirms that modeling of the electrical network for calculation of the reactive power value was correct.

The reactive power value consumed by the load generated by the active filter is calculated in sheet 2 (Fig. 4). The electrical network node for the installation of the active filter is identified through calculation. If the node is determined correctly, the active power losses in the network elements will be minimal.

Table 8. Apparent powers of interharmonics.

\begin{tabular}{ccccccc}
\hline \hline$S_{m}, \mathrm{VA}$ & \multicolumn{7}{c}{ Interharmonic } \\
\cline { 2 - 7 } & 1.5 & 3.5 & 5.5 & 17.5 & 19.5 & 11.5 \\
\hline Phase A & 16.6 & 6.0 & 5.1 & 7.5 & 8.5 & 5.1 \\
\hline Phase B & 17.2 & 4.8 & 5.0 & 1.9 & 2.7 & 3.7 \\
\hline Phase C & 18.0 & 7.3 & 6.4 & 9.2 & 9.7 & 5.0 \\
\hline$S_{m \Sigma A, B, C}$ & 51.8 & 18.1 & 16.5 & 18.6 & 20.9 & 13.8 \\
\hline$S_{m}, \mathrm{VA}$ & \multicolumn{7}{c}{ Interharmonic } \\
\cline { 2 - 7 } & 13.5 & 21.5 & 23.5 & 25.5 & 27.5 & 29.5 \\
\hline Phase A & 5.1 & 9.6 & 13.1 & 12.5 & 7.0 & 7.5 \\
\hline Phase B & 2.2 & 3.2 & 3.0 & 2.7 & 1.9 & 1.4 \\
\hline Phase C & 5.2 & 7.5 & 5.7 & 6.5 & 3.8 & 3.6 \\
\hline$S_{m \Sigma A, B, C}$ & 12.5 & 20.3 & 21.8 & 21.7 & 12.7 & 12.5 \\
\hline \hline
\end{tabular}


The apparent power values of harmonics and interharmonics to be eliminated by the active filter are calculated in sheets 3 and 4 . The powers are calculated by the results of measurements of harmonic load flow parameters and power quality indices at the electrical network node chosen for the active filter installation.

The apparent power of the active filter is calculated in sheet 5 of the program. Sheet 5 with the Table of the calculation results is presented in Fig. 5. The Table indicates the number of the network node for installation of the active filter, the value of the minimum active power losses, the reactive power of the fundamental frequency, the harmonic power, the interharmonic power, and the apparent power of the active filter.

\section{DETERMINATION OF THE APPARENT POWER OF THE ACTIVE FILTER HARMONICS FOR THE COAL GRADING PLANT OF THE COMPANY "CUA ONG-VINACOMIN"}

The management company of the coal grading plant has chosen node 45038 for the installation of an active filter in the power supply system (Fig. 1). The transformer supplying electrical power to the power supply system of the plant has five taps. They make it possible to have the voltages of $0.38 \mathrm{kV}, 0.39 \mathrm{kV}, 0.4 \mathrm{kV}, 0.41 \mathrm{kV}$, and $0.42 \mathrm{kV}$ at node 4143 . The calculation results show that if the voltage at node 4143 changes from $0.38 \mathrm{kV}$ to $0.42 \mathrm{kV}$, at 57 network nodes of $0.4 \mathrm{kV}$ the voltages range from $0.36 \mathrm{kV}$ to $0.39 \mathrm{kV}$. Hence, the requirements of [3] are not fulfilled. In this case, the load power factor at node 4143 takes the values from 0.88 to 0.99 , which meets partially the company requirements. Thus, the generation of reactive power can increase the voltage at the system nodes and the load power factor at node 4143 .

The computer program for calculating the active filter power following the proposed algorithm was applied to calculate the reactive power value of the active filter. The intermediate calculation results are presented in Tables 5 and 6.

The lowest active power losses in the network equal to $110 \mathrm{~kW}$ are observed with the tap of the $0.42 \mathrm{kV}$ transformer and the reactive power of the active filter of $580 \mathrm{kVAr}$. All the voltage conditions at the network nodes and node 4143 are met.

Harmonic powers were calculated based on measured parameters and are shown in Table 7. The active filter must have no less than $16 \mathrm{kVA}$ at each phase to eliminate harmonic currents. The total apparent power of harmonics in three phases is $40.3 \mathrm{kVA}$.

Table 8 presents the values of phase apparent power of some interharmonics and the total apparent powers of three phases, which were calculated by measured parameters. The total apparent power of interharmonics of three phases is $0.7 \mathrm{kVA}$, which is less than $1 \%$ of the harmonic power.

Figure 5 demonstrates the calculation results presented in the fifth sheet of the computer program. The Figure shows that at node 45038 of the active filter connection, the active power losses in the electrical network of the coal grading plant will be minimal and equal to $110 \mathrm{~kW}$ with the transformer tap of $0.42 \mathrm{kV}$ and the apparent power of the active filter of $621.1 \mathrm{kVA}$.

\section{CONCLUSION}

The measurements have shown that the load current contains harmonics and interharmonics, the indices $K_{U(n)}$ and $K_{U}$ exceed the normative values, and $\cos \varphi$ is lower than the norm.

Reduction in total harmonic distortion and increase in load power factor can be achieved with an active filter installed. The power of the active filter was determined using the developed optimization algorithm and measurements of load flow parameters.

The active filter power was determined for the coal grading plant of the company "Cua Ong-Vinacomin."

\section{ACKNOWLEDGMENT}

The research was carried out under State Assignment Project (No. FWEU-2021-0001) of the Fundamental Research Program of Russian Federation 2021-2030.

\section{REFERENCES}

[1] Circular No.39/2015/TT-BCT of the Ministry of Industry and Trade of Viet Nam for the distribution of Electrical Energy

[2] Electromagnetic compatibility of technical equipment. A general guide on harmonics and interharmonics measuring instruments and measurement for power supply systems and equipment connected thereto, GOST 30804.4.7-2013 (IEC 61000-4-7:2009), ISC Standard, 2013.

[3] National Technical Regulation on Electric Power, Viet Nam, 2015.

[4] B. Singh, K. Al-Haddad, A. Chandra, "A review of active filters for power quality improvement," IEEE Transactions on Industrial Electronics, vol. 46, no. 5, pp. 960-971, 1999.

[5] Gong Maozhong, Liu Hankui, Gu Jianjun, Xu Dianguo, "Active power filter based on novel current reference calculation," in Proc. IEEE ICIT'02, Thailand, 2003, DOI: 10.1109/ICIT.2002.1189916.

[6] C. H. da Silva, V. F. da Silva, L. E. B. da Silva, "Evaluation of Power-Ratings for Active Series Filters under Unbalanced Conditions for a Three Phase Four Wire System," in Proc. IEEE 36th PESC, Brazil, 2006, DOI: 10.1109/PESC.2005.1581638.

[7] Shekh Saddam Husen, Patel Pinkal J., "A literature review and industrial survey on active power filter," International journal of engineering development and research, vol. 2, no. 1, pp. 118-125, 2014.

[8] M.El-Habrouk, M.K. Darwish, P. Mehta, "Active power filter: A review," IEEE Proceedings in Electric Power Applications, vol. 147, no. 5, pp. 403-413, 2000. 
[9] Salvador Orts; Francisco J. Gimeno-Sales; Antonio Abellan; Salvador Segui-Chilet; Miguel Alcaniz, Rafael Masot, "Achieving maximum efficiency in three-phase systems with a shunt active power compensator based on IEEE Std. 1459, "IEEE Transactions on Power Delivery vol. 23, no. 2, pp. 812-822, 2008, DOI: 10.1109/TPWRD.2007.915910.

[10] Abbas Mariani, Luigi Piegari, Saeed Saeedallah Mortazavi, Mohammad-Sadegh Ghazizadeh, "Active Power Filter Commitment for Harmonic Compensation in Microgrids," in Proc. IECON 2019 - 45th Annual Conference of the IEEE IES, Portugal, 2019, DOI: 10.1109/IECON.2019.8927668.

[11] A. Kouzou, B. S. Khaldi, S. Saadi, M. O. Mahmoudi, M.S. Boucherit, "Apparent power ratio of the Shunt Active Power Filter," in Proc. 13th International EPE-PEMC, Poland, DOI: 10.1109/ EPEPEMC.2008.4635557.

[12] Gary W Chang, “A New Method for Determining Reference Compensating Currents of Three-Phase Shunt Active Power Filters," IEEE Power Engineering Review, vol. 22, issue 4, pp. 68-70, April 2002, DOI: 10.1109/MPER.2002.4312116.

[13] Faegheh Irannezhad, Seyed Hossein Hosseinian, Mehrdad Abedi, Behrooz Vahidis, "Using the Instantaneous Power Theory in order to control the current in the parallel active filter to compensate reactive power and reduction of harmonics," in Proc. PEDES 2012, India, DOI: 10.1109/ PEDES.2012.6484390.

[14] Jun Yang, Yue Wang, Zhaoan Wang, “A DSP controlled hybrid power filter used to compensate the harmonics and reactive power caused by electrical traction loads," IEEE Cat. No.03CH37491, Canada, 2004, DOI: 10.1109/PES.2003.1267397.

[15] Izzeldin Idris Abdalla, K. S. Rama Rao, N. Perumal, "Three-phase four-leg shunt active power filter to compensate harmonics and reactive power," in Proc. ISCI, Malaysia, 2011, DOI: 10.1109/ ISCI.2011.5958965.

[16] Operating Manual Network Analyzer PQ-Box 150 Power-Quality Evaluation Software, A. Eberle $\mathrm{GmbH}$, and Co. KG, 2017, [Online]. Available: https://www.a-eberle.de/sites/default/files/media/ BA_PQBox150_EN_201803.pdf (Accessed on Jan. 6, 2021).

[17] M. Maciazek, D Grabowski, and M. Pasko, "Active power filters - optimization of sizing and placement," Bulletin of the polish academy of sciences "Technical sciences," vol. 61, no. 4, pp. 847-853, 2013.

[18] Vahid Chakeri, M. T. Hagh, "Optimal Allocation of the Distributed Active Filters Based on Total Loss Reduction," Int. Journal of Smart Electrical Engineering, vol. 6, no. 4, pp. 171-175, 2017.

[19] Sarita Samal, Prakash Kumar Hota, Prasanta Kumar Barik, "Harmonics Mitigation by using Shunt Active Power Filter under Different Load Condition," in Proc. SCOPES, India, 2016, DOI: 10.1109/SCOPES.2016.
7955598.

[20] G. M. Mustafa, S. I. Gusev S.I. "Active filtercompensating devices of shunt and series type in electrical networks," Energetik, 2019, no. 8, pp. 3-10.

[21]O. N. Voitov, E. V. Popova, L. V. Semenova, "Algorithms for load flow calculation in electric networks

in terms of the temperature of overhead line conductors and their implementation," Elektrichestvo, 2013, no. 3, pp.19-26.

[22] Certificate of conformity no. ROSS RU.SP20. N00008 "Software SDO-7 for analysis, optimization of steady states and evaluation of electric power losses in electric networks" - Certificate scheme GOST R Gosstandart Rossii. Expiration date: from 31.01.2009 to 31.01.2012.

[23] A. E. Emanuel, "Three-Phase Nonsinusoidal and Unbalanced Conditions" in Power definitions and the physical mechanism of power flow, Worcester Polytechnic Institute, USA, IEEE PRESS, John Wiley and Sons, Ltd., Publication, 2010, pp. 185-203.

[24] Certificate of state registration of a computer program No. 2021613837 "Program for calculating the active filter power," Federal Service for Intellectual Property. Expiration date: from 15.01.2021 to 15.01.2035.

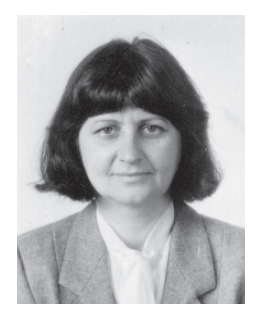

Lidia Kovernikova is a Senior Researcher of Melentiev Energy Systems Institute of the Russian Academy of Sciences, Irkutsk, Russia. She graduated from Novosibirsk Electrotechnical Institute in 1976. L.I. Kovernikova received her Ph.D. degree in engineering from the Siberian Energy Institute in 1995. Her research interests include modeling non-sinusoidal conditions of electrical power systems, analyzing the power quality in electrical networks, and developing technical means to improve the power quality.

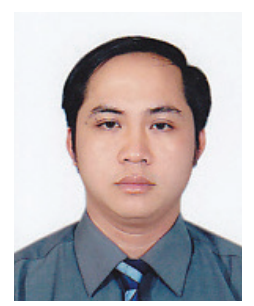

Bui Ngoc Hung is a graduate student of Irkutsk National Research Technical University, Irkutsk, Russia. He graduated from Ha Noi University of Mining and Geology in 2006. Bui Ngoc Hung completed his Ph.D. in electrical engineering at $\mathrm{Ha}$ Noi University of Mines and Geology. His research interests include power quality in electrical networks and developing technical means to improve the power quality. 


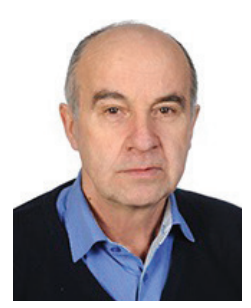

Oleg Voitov is a Senior Researcher of Melentiev Energy Systems Institute of the Russian Academy of Sciences, Irkutsk, Russia. He graduated from Moscow Power Engineering Institute in 1971. O.N. Voitov received his Ph.D. degree in engineering from the Siberian Energy Institute in 1993. His research interests include modeling the steady-state conditions of electric power systems in a single-line representation and phase coordinates, the development of algorithms for analyzing and optimizing instantaneous and short-term operating conditions in the context of discrete parameter changes.

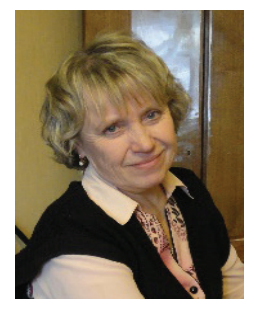

Lyudmila Semenova is the Lead Engineer of Melentiev Energy Systems Institute of the Russian Academy of Sciences, Irkutsk, Russia. L. V. Semenova graduated from Irkutsk Polytechnic Institute in 1974. Her research interests include the development and implementation of methods and models for studying the functioning of power systems.

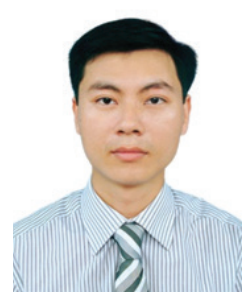

Pham Duc Tien is a power engineer at the Wong Bi - TKV - Vinasovin Coal Company in Viet Nam. He teaches at the College of Construction of the Ministry of Construction. He graduated from $\mathrm{Ha}$ Noi University of Mining and Geology in 2006. Pham Duc Tien completed his master's degree in electrical engineering at $\mathrm{Ha}$ Noi University of Mining and Geology. His research interests include power quality, development of technical methods to improve it, safety and operation of high voltage power supply.

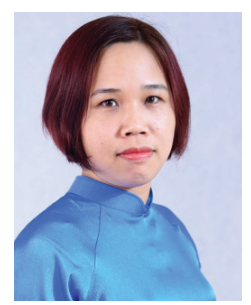

Ha Thi Chuc is a lecturer at the University of Mining and Geology, Ha Noi, Viet Nam. She graduated from Ha Noi University of Transport and Communication in 2008. Ha Thi Chuc completed her Ph.D. in Electrical and Electronic Engineering at the Ha Noi University of Transport and Communication. Her research interests include power quality, developing technical means to improve the power. 